\title{
Host-feeding preference of Phlebotomus orientalis (Diptera: Psychodidae) in an endemic focus of visceral leishmaniasis in northern Ethiopia
}

\author{
Araya Gebresilassie ${ }^{1,2^{*}}$, Ibrahim Abbasi ${ }^{3}$, Essayas Aklilu${ }^{1}$, Solomon Yared ${ }^{2}$, Oscar David Kirstein ${ }^{3}$, Aviad Moncaz $^{3}$, \\ Habte Tekie ${ }^{1}$, Meshesha Balkew ${ }^{4}$, Alon Warburg ${ }^{3}$, Asrat Hailu ${ }^{5}$ and Teshome Gebre-Michael ${ }^{4}$
}

\begin{abstract}
Background: Blood-feeding behavior studies are important for estimating the efficiency of pathogen transmission and assessing the relative human disease risk. However, in Ethiopia and other parts of East Africa there are large remaining gaps in identifying the feeding habits of Phlebotomus orientalis, the vector of Leishmania donovani. The aim of the study was to determine the blood feeding patterns of $P$. orientalis in Tahtay Adiyabo district, northern Ethiopia.

Methods: For bloodmeal analysis, sandflies were collected from three different villages of Tahtay Adiyabo district using CDC light traps, sticky traps, and pyrethrum spray catches. Bloodmeal of engorged female sandflies was identified using cytochrome (cyt) b-PCR and reverse-line blotting (RLB) and enzyme linked immunosorbent assay (ELISA) assays.

Results: Most (637/641) of the females analyzed were $P$. orientalis. Successful identification of the host from bloodmeals was achieved in 83.03 and $92.1 \%$ using cyt $b$ PCR-RLB and ELISA, respectively. Bloodmeal analysis of $P$. orientalis females revealed that they have a range of hosts with predominant preference to bovines followed by donkey, human, goat, sheep, dog, and camel.

Conclusion: Results obtained from bloodmeal analyses demonstrate that the feeding preference of $P$. orientalis is mainly zoophilic, which could vary depending on the availability of hosts.
\end{abstract}

Keywords: Bloodmeal, Host preference, Phlebotomus orientalis, Tahtay Adiyabo, Visceral leishmaniasis

\section{Background}

Worldwide, leishmaniasis endangers 350 million people in 98 countries and 3 territories, accounting for about 12 million clinical cases each year [1,2]. This disease is characterized by a spectrum of clinical manifestations, including cutaneous, mucocutaneous and visceral forms. Visceral leishmaniasis (VL), which its causative agent is L. donovani, is a common infection and a major public health concern in East African countries with approximately 29,400 to 56,700 new cases each year [2]. In Ethiopia, several active foci of VL are located in

\footnotetext{
* Correspondence: shambe2006@yahoo.com

'Department of Zoological Sciences, Addis Ababa University, Addis Ababa, Ethiopia

2Department of Biology, College of Natural Science, Jigjiga University, Jigjiga, Ethiopia

Full list of author information is available at the end of the article
}

southwestern savannah, the southeastern semiarid lowlands, and the Humera-Metema lowlands [3-5]. Recently, new endemic focus has appeared in the semi-arid lowlands of northwestern Tigray Regional State, north Ethiopia, previously considered free from the disease [6].

Transmission of VL occurs when a female sandfly acquires infection feeding on an infected host and transmits the parasite during subsequent feedings after completion of the gonotrophic cycle, during which the parasite takes full development in the gut $[7,8]$. In Sudan, South Sudan, northern and southwestern Ethiopia, $P$. orientalis has been indicated as the main vector of VL [9-11].

The natural blood feeding habits of sandfly vectors under natural conditions are determined by examining the bloodmeal origin of field-collected specimens [11-15]. 
Previously, the host preference of $P$. orientalis in Ethiopia was determined by identification of sources of bloodmeals by counter current immuno-electrophoresis (CCIE) technique [16] and enzyme linked immunosorbent assay (ELISA) [11]. In the Humera-Metema plains, $P$. orientalis exhibits zoophilic behavior by predominantly feeding on bovine blood [10]. Similarly, around Awash Valley (northeast of Ethiopia), bloodmeal analysis of $P$. orientalis revealed that the vector species mainly feeds on domestic animals found in the area [16]. Proper characterization of the feeding habits of sandflies is crucial for developing effective vector control programs. However, no bloodmeal source identification in wild caught $P$. orientalis females was performed in the new VL endemic area of Tahtay Adiyabo district.

Therefore, bloodmeal source identification of wild caught $P$. orientalis in this $\mathrm{VL}$ endemic area was conducted using cytochrome $b$ PCR (Cyt $b$ ) and reverse line blotting (RLB) and enzyme-linked immunosorbent assay (ELISA).

\section{Methods \\ Study area}

The fieldwork of the study was conducted in three villages of the rural district of Tahtay Adiyabo $\left(14^{\circ} 23^{\prime} 41^{\prime \prime} \mathrm{N} /\right.$ $\left.37^{\circ} 46^{\prime} 15^{\prime \prime} \mathrm{E}\right)$ in the Tigray Regional State, northern Ethiopia. The topography of the study area is predominantly lowland plain except in the southwest, where it is mountainous. Sheraro, the administrative center of the district, lies 1,028 meters above sea level and has a latitude and longitude of $14^{\circ} 23^{\prime} 41^{\prime \prime} \mathrm{N} / 37^{\circ} 46^{\prime} 15^{\prime \prime} \mathrm{E}$, respectively. The town is also located about $1,117 \mathrm{~km}$ north of Addis Ababa. The three villages were Ademeyti, Lemlem, and Mentebteb. The villages of Ademeyti and Lemlem are approximately 17 and $6 \mathrm{kms}$ northwest and west of Sheraro town, respectively. The third village, Mentebteb is located about $13 \mathrm{~km}$ southwest of Sheraro town. The distance between the three villages is about $8-12 \mathrm{~km}$.

The climate is generally sub-tropical-arid, with an extended dry period of nine to ten months. The area has a uni-modal pattern of rainfall (July-September) with a mean annual precipitation of about $600 \mathrm{~mm}$ (Ethiopian National Meteorological Agency). March to May is the hottest part of the year with an average temperature of $39{ }^{\circ} \mathrm{C}$ at noon and January is the coldest one with an average temperature of $14.2{ }^{\circ} \mathrm{C}$ at night.

The villages are situated on hilly outcrops surrounded by large farm fields of vertisol alternating with large tracts of red clay soil. The inhabitants are mainly engaged in the production of cereals and oilseeds and raising different domestic animals such as cattle, sheep, goats, dogs, donkeys, camels and chickens. Furthermore, a wide range of wild animals, including hares, ground squirrels, rodents, reptiles, white-tailed mongoose and foxes are either occasionally or commonly seen.

\section{Sampling and handling of blood fed females}

Females of $P$. orientalis and other Phlebotomus spp. ( $P$. papatasi, $P$. bergeroti and $P$. martini) with fresh bloodmeals were collected from three different villages of the study area using CDC light traps, sticky traps and pyrethrum spray catch methods between May 2011 and April 2012. Collection of blood-fed specimens from indoors, peri-domestic biotopes (places with human and animal shelters), and agricultural fields on the periphery of settlements was carried out twice a month for three consecutive nights.

Five CDC light traps suspended with $40-50 \mathrm{~cm}$ above the ground level were randomly distributed to representative locations of peri-domestic biotopes and agricultural fields. Fifty sticky traps (white A4 sized polypropylene boards coated with sesame oil) were also used for sampling blood-fed females from indoors, peri-domestic and agricultural fields. Moreover, indoor resting sandflies were sampled in the morning (6:00 to 9:00) from ten other randomly selected houses by the application of pyrethrum spray catch method.

The head of each blood-fed female was carefully separated from the thorax and slide-mounted in Hoyer's medium for species identification using taxonomic keys $[17,18]$. The remaining body (thorax and abdomen) were individually placed in empty antibiotic capsules with silica gel grains and cotton pads inside. Likewise, some of blood-fed females were preserved in $70 \%$ ethanol for later DNA extraction. In the laboratory, the specimens were stored at $-20{ }^{\circ} \mathrm{C}$ for later bloodmeal analysis using ELISA [19] and Cyt $b$ PCR and RLB methods [14].

\section{Bloodmeal determination}

Of 824 blood-fed sandflies (820 P. orientalis, 1 P. papatasi, $1 P$. bergeroti, and 2 P. martini) collected by CDC light traps, sticky traps and pyrethrum spray catches, 641 were randomly selected for bloodmeal identification (Table 1). Selection of sandfly specimens was based on village, capture sites and sampling periods to obtain a representative samples. One hundred and eighty three of those randomly

Table 1 Number of blood fed sandflies tested, listed by species, location, and method

\begin{tabular}{llllllll}
\hline Species & \multicolumn{2}{l}{ Villages } & \multicolumn{3}{l}{ Total } \\
& \multicolumn{2}{l}{ Ademeyti } & \multicolumn{2}{l}{ Lemlem } & \multicolumn{2}{l}{ Mentebteb } & \\
& ELSA & RLB & ELSA & RLB & ELSA & RLB & \\
\hline P. orientalis & 220 & 87 & 230 & 68 & 7 & 25 & 637 \\
P. papatasi & 0 & 0 & 0 & 1 & 0 & 0 & 1 \\
P. bergeroti & 0 & 0 & 0 & 1 & 0 & 0 & 1 \\
P. martini & 0 & 1 & 0 & 0 & 1 & 0 & 2 \\
\hline
\end{tabular}


drawn blood-fed samples were analyzed by Cyt $b$ PCRRLB (Table 1). The remaining 458 samples were processed by ELISA method.

\section{Cytochrome $b$ PCR and reverse line blotting DNA extraction}

DNA was extracted individually from blood-fed females of sandflies by digestion in a total volume of $200 \mu \mathrm{L}$ of lysis buffer $(50 \mathrm{mM} \mathrm{NaCl}, 10 \mathrm{mM}$ ethylenediaminetetraacetic acid [EDTA], $50 \mathrm{mM}$ Tris- $\mathrm{HCl} \mathrm{pH} \mathrm{7.4,} 1$ \% triton $\mathrm{X}-100$, and $200 \mu \mathrm{g} / \mathrm{mL}$ of proteinase $\mathrm{K})$. This was followed by extraction with phenol-chloroform and precipitation using ethanol. The precipitated DNA was suspended in Tris-EDTA (TE, $10 \mathrm{mM}$ Tris- $\mathrm{HCl} \mathrm{pH}$ 7.4, 1 mM EDTA) buffer at a concentration of $50 \mu \mathrm{L}$.

\section{PCR amplification of the mtDNA cyt $b$ gene}

A 344 bp sequence of the conserved region of the mitochondria cyt $b$ gene was amplified using bio-tinilated universal primers designed by Abbasi et al. (2008). The sequences of the primers used were Cyto1: 5'-CCA TCA AAC ATC TCA GCA TGA TGA AA-3' (forward primer) and Cyto2: 5'-CCC CTC AGA ATG ATA TTT GTC CTC-3' (reverse primer). The cyt $b$ region was amplified in a total reaction volume of $50 \mu \mathrm{L}$ consisting of $25 \mu \mathrm{L}$ Hot start taq Master mix (1.5 mM MgCl 2 , $200 \mu \mathrm{L}$ each deoxyribonucleotide triphosphates (dNTP) and $75 \mathrm{mM} \mathrm{KCl}, 10 \mathrm{mM}$ Tris $\mathrm{HCl} \mathrm{pH8.8)} \mathrm{and} 0.5 \mu \mathrm{M}$ of each primer and $5 \mu \mathrm{L}$ of genomic DNA. The thermo cyclic conditions consisted of $95^{\circ} \mathrm{C}$ for $5 \mathrm{~min}, 35$ cycles at $94{ }^{\circ} \mathrm{C}$ for $30 \mathrm{~s}, 55{ }^{\circ} \mathrm{C}$ for $30 \mathrm{~s}$, and $72{ }^{\circ} \mathrm{C}$ for $1 \mathrm{~min}$; followed by elongation step at $72{ }^{\circ} \mathrm{C}$ for $10 \mathrm{~min}$. Cow blood was used as positive control and double distilled water as negative control. The amplified PCR products were used as probes in RLB hybridization reactions followed by chromogenic detection. The methods used by Abbasi et al. [14] were followed for immobilization, hybridization, and detection.

\section{Species-Specific Probes, Immobilization, Hybridization, and Detection}

Species-specific 5'-amino-linked oligonucleotide probes for human, cow, sheep, goat, camel, donkey, dog, mice, brown rat, chickens and a general avian probe developed by Abbasi et al. [14] were used in the current study.

The synthetic 5'-end amino modified oligonucleotide probes were covalently linked to nylon membranes through the formation of amide bonds between the carboxyl groups on the nylon and the amino groups linked to the oligonucleotides. Biodyn C (Pall Biomedical, Fajardo, Puerto Rico) nylon membrane were activated in $0.1 \mathrm{~N} \mathrm{HCl}$ for $5 \mathrm{~min}$, rinsed with $\mathrm{DH}_{2} \mathrm{O}$ and soaked in $10 \%$ 1-ethyl-3-[3-dimethylaminopropyl] carbodiimide (EDC) (Sigma, St. Louis, MO, USA) for 15 minutes. The membranes were rinsed in $\mathrm{DH}_{2} \mathrm{O}$ water and air-dried. Species-specific, 5'-end amino modified oligonucleotides were diluted to $5 \mathrm{p}$ moles/ $\mu \mathrm{L}$ and applied to the membrane in line format using a manifold blotter apparatus.

The nylon membrane sheets with the above mentioned probes were cut at a right angle to the direction of the blot so that each strip contained a section of each probe. Strips were incubated in prehybridization solution (2X SSC [0.15 M NaC1, $0.015 \mathrm{M}$ sodium citrate], $0.1 \%$ sodium dodecyl sulphate [SDS]) for $30 \mathrm{~min}$ at $45{ }^{\circ} \mathrm{C}$ with gentle shaking. Biotinylated PCR products were denatured by boiling for $5 \mathrm{~min}$ and applied to the membrane strips. Hybridization was performed at $46{ }^{\circ} \mathrm{C}$ for $1 \mathrm{~h}$ followed by a single wash with $0.7 \mathrm{X}$ SSC, $0.1 \%$ SDS for 20 minutes. Hybridized biotinylated DNA was detected by incubating the strips in streptavidin-horse radish peroxidase (HRP; diluted in 2X SSC, $0.1 \%$ SDS) for $30 \mathrm{~min}$ at room temperature. Strips were washed briefly 3 times in $2 \mathrm{X}$ SSC, $0.1 \%$ SDS. For chromogenic detection, a freshly prepared solution containing $0.1 \mathrm{mg} / \mathrm{mL}$ of 3,3'5,5' tetramethylbezidine (Sigma), $0.003 \% \mathrm{H}_{2} \mathrm{O}_{2}$ in $0.1 \mathrm{M}$ sodium citrate ( $\mathrm{pH}$ 5.0) was added. Enhanced chemiluminescent (ECL) detection was performed immediately after streptavidin-HRP incubation and washing steps using EZ-ECL detection kit (Biological Industries, Beit Haemek, Israel).

\section{Serologic analysis}

Bloodmeal origins of freshly fed sandflies were also determined using a direct enzyme (ELISA). The abdomen and thorax of each blood-fed sandfly was individually triturated in $2 \mathrm{ml}$ Eppendorf tubes with micro-tissue grinders to which $50 \mu \mathrm{l}$ of $0.01 \mathrm{M}$ phosphate buffered saline (PBS), pH 7.2 was added. Samples were then mixed with PBS to desired dilutions and kept in the refrigerator $\left(4{ }^{\circ} \mathrm{C}\right)$ until tested. Sandfly triturate $(50 \mu \mathrm{l})$ was diluted in PBS (3:50) and $50 \mu \mathrm{l}$ was added to wells of polyvinyl chloride, U-shaped, 96-well micro titer plates (Dynatech Laboratories, Inc., Alexandria), which were covered and incubated at $4{ }^{\circ} \mathrm{C}$ overnight. Plates were washed three times with phosphate-buffered saline, Tween 20, pH 7.2. The plate was blocked using $200 \mu \mathrm{l}$ of bovine serum albumin/carbonate-bicarbonate buffer (200 mg of bovine serum albumin in $20 \mathrm{ml}$ of carbonate-bicarbonate buffer), and left to incubate for $2 \mathrm{~h}$ at room temperature, washed three times with phosphate-buffered saline, Tween 20, pH 7.2. This was followed by the dilution of host-specific peroxidase-conjugated anti-IgG antibodies (anti-human, anti-bovine, anti-donkey, anti-dog, antigoat and anti-sheep) diluted at 1:2,000; 1:250 1:5000, $1: 5000,1: 5000$ and 1:5000 in $0.5 \%$ boiled casein containing $0.025 \%$ Tween 20, respectively. Cross-reactions were noted between anti-goat and anti-sheep with the blood samples of cow, human, and donkey and vice versa. 
Thus, mixed bloodmeals of these antibodies were excluded. The boiled casein was prepared by dissolving $5 \mathrm{~g}$ casein in $100 \mathrm{ml}$ of $0.1 \mathrm{~N} \mathrm{NaOH}$ by boiling, adding $900 \mathrm{ml} \mathrm{PBS}$, adjusting $\mathrm{pH}$ to 7.2 adding $0.1 \mathrm{~g}$ Thimerosal (Sodium ethylmercurithiosalicylate) and $0.02 \mathrm{gm}$ phenol red. After $1 \mathrm{~h}$ incubation, wells were washed three times with $200 \mu \mathrm{l}$ PBS Tween 20, and then $100 \mu \mathrm{l}$ of ABTS (2, 2-azino-di- [3-ethyl benzthiazoline sulfonate]) peroxidase substrate (Kirkegaad and Perry Laboratories, Inc.) was added to each well. Negative controls were prepared using unfed laboratory-reared female $P$. orientalis while positive serum controls were done by making host serum: PBS dilutions of 3:50 [12]. Each plate contained a positive control of host species; four negative controls and test samples (1:50 dilution in PBS for all cases). Results were visually assessed, and absorbance was measured with an ELISA reader at $405 \mathrm{~nm}$ approximately 30 minutes after addition of substrate solution. Test samples were considered positive if absorbance values exceeded the mean plus three times the standard deviation of four negative controls.

\section{Results}

\section{Cyt $b$ PCR-RLB}

A total of 183 blood-fed Phlebotomus spp. (180 P. orientalis, 1 P. papatasi, 1 P. bergeroti, and 1 P. martini) were analyzed for bloodmeal identification and 168 (91.80 \%) were positive to cyt $b$ PCR. The remaining 15-bloodmeal samples of $P$. orientalis did not produce distinctive bands for cyt $b$ amplifications. All the PCR-positive samples were used for the identification of bloodmeals imbibed in female sandflies using RLB (Table 2). Successful identification of the host from bloodmeals was achieved in $137 / 165,1 / 1,1 / 1$ and $1 / 1$ of $P$. orientalis, $P$. papatasi,
P. martini and P. bergeroti, respectively. However, some of the samples (i.e., 28) which were positive for cyt $b$ PCR amplification did not produce bands (Table 2).

A high proportion of $P$. orientalis females were found to have fed on bovine blood in all the three study villages (Table 2). In Ademeyti, out of 87 bloodmeals tested 41 (51.25\%), 10 (12.50\%), 3 (3.75 \%), 1 (1.25\%) and 10 (12.50\%) contained blood of bovine, human, goat, sheep and mixed hosts, respectively. In Lemlem, $58.30 \%$ and $13.30 \%$ of $P$. orientalis fed on bovine and human blood respectively while the remaining $31.67 \%$ fed on the blood of other hosts. The proportions of $P$. orientalis detected to be positive to bovine, human and goat bloodmeal origins in Mentebteb were $64.00 \%, 16.00 \%$, and $2.00 \%$, respectively. Besides, large proportions of unidentified bloodmeals were obtained in Ademeyti and Lemlem villages compared to Mentebteb. One specimen of $P$. martini was positive to human blood in Ademeyti. Similarly, $P$. papatasi and $P$. bergeroti each with one specimen contained human blood origin.

In terms of collection habitats, human blood indices for P. orientalis were $25.00 \%, 6.54 \%$ and $26.32 \%$ indoor, peridomestic and agricultural fields, respectively (Table 3 ). For bovines, however, it was $20.00 \%$ indoor, $66.36 \%$ in peridomestic and $44.74 \%$ in agricultural fields. A single bloodmeal source of sheep and camel was detected in $P$. orientalis. Mixed bloodmeals in P. orientalis females, including human-cow, human-cow-goat-camel, human-cowgoat, cow-goat, and cow-sheep were detected using the PCR-RLB technique (Tables 2 and 3; Fig. 1).

\section{ELISA assay}

Table 4 shows the bloodmeal origins of $P$. orientalis from different sampling villages. In this assay, 458

Table 2 Bloodmeal sources of $P$. orientalis captured from three different villages and identified using Cyt $b$ PCR and RLB

\begin{tabular}{|c|c|c|c|c|}
\hline Sources of bloodmeal & Ademeyti & Lemlem & Mentebteb & Total (\%) \\
\hline Bovine & $41(51.25)$ & $35(58.33)$ & $16(64)$ & $92(55.76)$ \\
\hline Human & $10(12.5)$ & $8(13.33)$ & $4(16)$ & $22(13.33)$ \\
\hline Goat & $3(3.75)$ & $3(5)$ & $2(8)$ & $8(4.85)$ \\
\hline Sheep & $1(1.25)$ & 0 & 0 & $1(0.61)$ \\
\hline Camel & 0 & 0 & $1(4)$ & $1(0.61)$ \\
\hline Human-Bovine & $4(5)$ & $2(3.33)$ & 0 & $7(4.24)$ \\
\hline Human-Bovine-Goat & $3(3.75)$ & 0 & 0 & $3(1.82)$ \\
\hline Human-Bovine-Goat-Camel & $1(1.25)$ & 0 & 0 & $1(0.61)$ \\
\hline Bovine-Goat & $1(1.25)$ & $1(1.67)$ & 0 & $1(0.61)$ \\
\hline Bovine-Sheep & $1(1.25)$ & 0 & 0 & $1(0.61)$ \\
\hline Unidentified & $15(18.75)$ & $11(18.33)$ & $2(8)$ & $28(16.97)$ \\
\hline Total (+cyt b PCR) & 80 & 60 & 25 & 165 \\
\hline Negative & 7 & 8 & 0 & 15 \\
\hline Total (tested) & 87 & 68 & 25 & 180 \\
\hline
\end{tabular}


Table 3 Number and percentage of bloodmeal sources of $P$. orientalis collected from different habitats and detected by Cyt b PCR-RLB

\begin{tabular}{llll}
\hline Sources of bloodmeal & Indoor & Peri-domestic & Agricultural field \\
\hline Bovine & $4(20)$ & $71(66.36)$ & $17(44.74)$ \\
Human & $5(25)$ & $7(6.54)$ & $10(26.32)$ \\
Goat & $2(10)$ & $1(0.93)$ & $5(13.16)$ \\
Sheep & 0 & 0 & $1(2.63)$ \\
Camel & 0 & 0 & $1(2.63)$ \\
Human-Bovine & $3(15)$ & $4(3.74)$ & 0 \\
Human-Bovine-Goat & $3(15)$ & 0 & 0 \\
Human-Bovine-Goat-Camel & $1(5)$ & 0 & 0 \\
Bovine-Goat & 0 & $1(0.93)$ & 0 \\
Bovine-Sheep & 0 & 0 & $1(2.63)$ \\
Unidentified & $2(10)$ & $23(21.5)$ & $3(7.89)$ \\
Total (+cyt $b$ PCR) & 20 & 107 & 38 \\
Negative & 0 & 12 & 3 \\
Total (tested) & 20 & 119 & 41 \\
\hline
\end{tabular}

blood-fed females of $P$. orientalis $(\mathrm{n}=457)$ and $P$. martini $(\mathrm{n}=1)$ were analyzed, and a general reactivity index of $92.1 \%$ was obtained against antibodies of test animals (human, bovine, donkey, dog, and goat/sheep). Bloodmeal origins from bovine (46.6\%), donkey (9.63\%), human $(6.78 \%)$, goat/sheep (5.03 \%), and dog (1.75\%) were detected in female $P$. orientalis (Table 4). As well, $103(22.54 \%)$ of female P. orientalis had bloodmeals of mixed origin (Table 4). Hosts for the remaining $8.0 \%$ of the blood samples, could not be identified. One
Table 4 Results of ELISA assays on bloodmeals of $P$. orientalis collected from different study villages of Tahtay Adiyabo district

\begin{tabular}{lllll}
\hline Sources of bloodmeal & Ademeyti & Lemlem & Mentebteb & Total \\
\hline Bovine & $113(51.36)$ & $98(42.61)$ & $2(28.57)$ & $213(46.61)$ \\
Donkey & $16(7.27)$ & $25(10.87)$ & $3(42.86)$ & $44(9.63)$ \\
Human & $12(5.45)$ & $17(7.39)$ & $2(28.57)$ & $31(6.78)$ \\
Goat/sheep & $13(5.45)$ & $11(4.78)$ & 0 & $23(5.03)$ \\
Dog & $3(1.36)$ & $5(2.17)$ & 0 & $8(1.75)$ \\
Bovine-Donkey-Dog & $10(4,55$ & $19(8.26)$ & 0 & $29(6.35)$ \\
Bovine-Dog & $12(5.45)$ & $8(3.48)$ & 0 & $20(4.38)$ \\
Bovine-Donkey & $1(0.45)$ & 0 & 0 & $1(0.22)$ \\
Donkey-Dog & $4(1.82)$ & $6(2.61)$ & 0 & $10(2.19)$ \\
Human-Bovine-Dog & $2(0.92)$ & $0(0)$ & 0 & $2(0.44)$ \\
Human-Bovine & $2(0.92)$ & $7(3.04)$ & 0 & $9(1.97)$ \\
Human-Bovine-Donkey & $11(5)$ & $10(4.35)$ & 0 & $21(4.6)$ \\
Human-Donkey & 0 & $5(2.17)$ & 0 & $5(1.1)$ \\
Human-Dog & $1(0.45)$ & $2(0.87)$ & 0 & $3(0.66)$ \\
Human-Donkey-Dog & $1(0.45)$ & $2(0.87)$ & 0 & $3(0.66)$ \\
Unidentified & $20(9.09)$ & $15(6.52)$ & 0 & $35(7.66)$ \\
Total & 220 & 230 & 7 & 457 \\
\hline & & & & \\
\hline
\end{tabular}

specimen of P. martini collected from Mentebteb also had mixed bloodmeal of bovine-donkey-dog.

Further classifications of the bloodmeals by sampling villages and habitat types are presented in Tables 4 and 5. In Ademeyti and Lemlem, the highest proportion of bloodmeal index was for bovine, constituting $51.36 \%$ and $42.61 \%$, respectively (Table 4). Whereas in Mentebteb the highest, bloodmeal index was for donkey

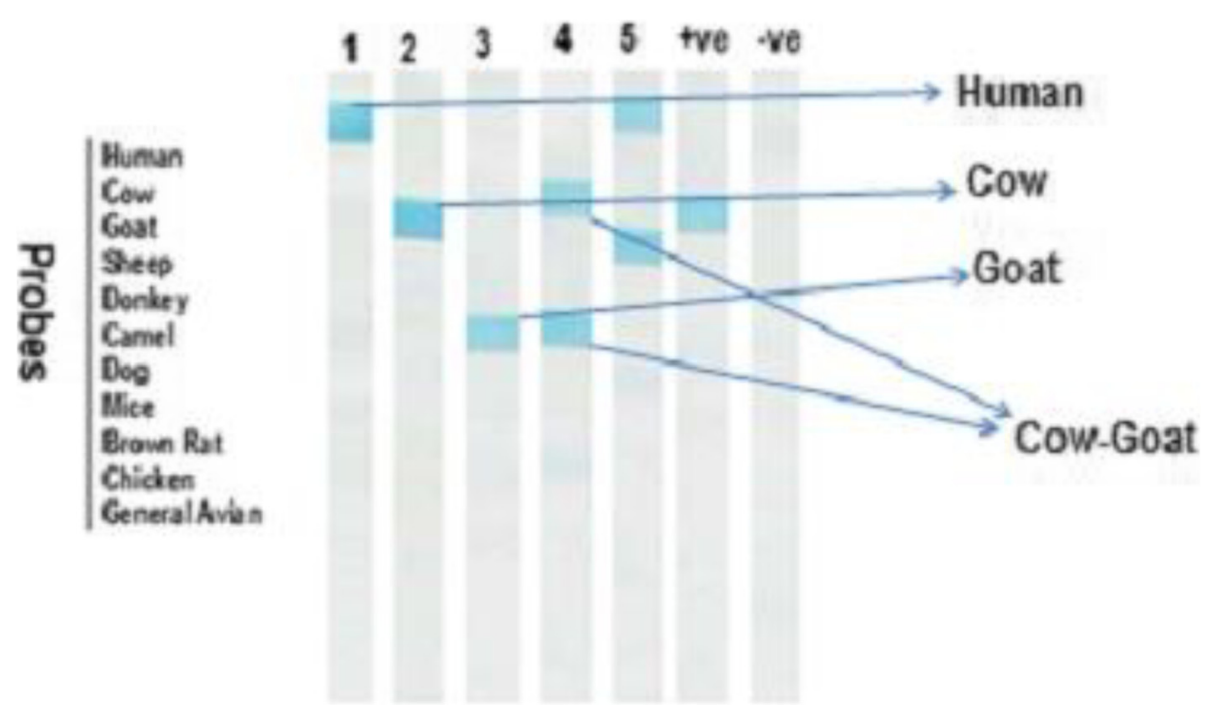

Fig. 1 Representative RLB results of Cyt $b$ PCR products from blood-fed, P. orientalis. Sample number 1: human blood. Sample 2: cow blood. Sample 3: goat blood. Sample 4: cow and goat. Sample 5: human and cow blood. +ve sample is cow blood. -ve sample with no PCR product 
Table 5 Bloodmeal origins of $P$. orientalis collected from indoor, peri-domestic and agricultural field as determined by ELISA assay

\begin{tabular}{llll}
\hline Sources of bloodmeal & Indoor & Peri-domestic & Agricultural field \\
\hline Bovine & $8(34.78)$ & $176(51.76)$ & $29(30.85)$ \\
Donkey & $4(17.39)$ & $34(10)$ & $6(6.38)$ \\
Human & $6(26.09)$ & $22(6.47)$ & $3(3.19)$ \\
Goat/sheep & $2(8.7)$ & $8(2.35)$ & $13(13.83)$ \\
Dog & 0 & $8(2.35)$ & 0 \\
Bovine-Donkey-Dog & $2(8.7)$ & $14(4.12)$ & $13(13.83)$ \\
Bovine-Dog & 0 & $18(5.29)$ & $2(2.13)$ \\
Bovine-Donkey & 0 & $1(0.29)$ & 0 \\
Donkey-Dog & 0 & $6(1.76)$ & $4(4.25)$ \\
Human-Bovine-Dog & 0 & $2(0.59)$ & 0 \\
Human-Bovine & 0 & $8(2.35)$ & $1(1.06)$ \\
Human-Bovine-Donkey & $1(4.35)$ & $17(5)$ & $3(9.57)$ \\
Human-Donkey & 0 & $4(1.18)$ & $1(1.06)$ \\
Human-Dog & 0 & $2(0.59)$ & $1(1.06)$ \\
Human-Donkey-Dog & 0 & $2(0.59)$ & $1(1.06)$ \\
Unidentified & 0 & $18(5.29)$ & $17(18.09)$ \\
Total & 23 & 340 & 94 \\
\hline
\end{tabular}

(42.86\%) followed by bovine and human each having $28.57 \%$.

Blood feeding preferences of $P$. orientalis females also varied according to sampling habitats. P. orientalis females caught indoor contained bloodmeal origin in the following order: $34.78 \%, 26.09 \%, 17.39 \%$, and $8.70 \%$ for bovine, human, donkey, and goat/sheep, respectively (Table 5). In peri-domestic habitat, the highest host preference was for bovine $(51.76 \%)$ followed by donkey (10.00\%), human (6.47\%), dog (2.35\%) and goat/sheep (2.35\%). Similarly, the index of bloodmeal for different hosts in agricultural fields ranged from $30.85 \%$ of bovine bloodmeal origin to $3.19 \%$ of human host blood.

\section{Discussion}

In the current study, wild-captured $P$. orientalis females were demonstrated to depend largely on bovine bloodmeals, constituting $55.76 \%$ in PCR-RLB and $46.61 \%$ in ELISA tests. Similar results have been previously recorded for P. orientalis in northeast [16] and northwest of Ethiopia [11, 20]. In addition, the role played by cattle as bloodmeal sources for $P$. argentipes was largely indicated in various studies in India $[15,21,22]$. Large proportions of $P$. orientalis contained bloodmeals of bovine, which could be related to their availability and abundance as well greater release of kairomones, compared to other animal hosts in the area [23, 24]. Secondly, this could also be associated with capturing of most engorged $P$. orientalis females from peri-domestic biotopes. In our study area, cattle are raised in large numbers by villagers and are usually kept in enclosures close to residential houses. The accessibility of bovine blood hosts to questing $P$. orientalis females in the peridomestic habitat may provide zooprophylactic barrier potentially reducing human-vector contact, or it may aggravate the risk of VL infection. Thus, the putative role of cattle in the epidemiology of VL requires further validation.

Less proportion (9.6\%) of donkey bloodmeal origin was detected in the bloodmeal analysis. However, a recent host choice study in the same area showed that $P$. orientalis females are attracted and engorged avidly on donkey [25]. Discrepancy between the two methods could be attributed to the lesser abundance of donkeys in the study villages, thereby reducing their accessibility for sandfly bite. The role of donkeys in the epidemiology of VL is a subject of further study.

Importantly, $8.50 \%$ (in both assays) of the wild-caught specimens of $P$. orientalis females contained human blood origin. This finding supports the likelihood that $P$. orientalis is the vector of VL in these parts of East Africa since human biting by a sandfly vector is a minimum requirement for disease transmission [26]. Furthermore, bloodmeal source from goat, sheep, dog, and camel was detected, showing the evidence of being opportunistic feeder with higher degree of zoophily on a broad range of host species.

The apparent presence of multiple bloodmeals from a single specimen in some females is a strong evidence of the eclectic diet of $P$. orientalis. This behavior is a common phenomenon in sandflies and therefore it may be a result of the difficulties sandflies face in freely engorging on a single host due to host defensive mechanisms, little or no exposed host skin or the difficulty to locate adequate skin blood capillaries [13]. For instance, $P$. orientalis females analyzed for bloodmeal in northeast Ethiopia had $54.30 \%$ multiple bloodmeals from available vertebrate hosts [18], the predominant being cattlecamel hosts $(60.00 \%)$. This host-feeding behavior can influence pathogen transmission through increased frequency of vector-human contact, or possibly reduce vector-human contact if some bloodmeals are taken from alternative mammalian hosts.

Results of PCR-RLB assay were comparable with ELISA in the detection sensitivity of bloodmeal hosts in field-collected females of $P$. orientalis in this study (91.80\% versus $92.20 \%)$. However, PCR-RLB method is known to possess the unique ability to analyze bloodmeal from the blood-fed sandflies having minute quantities of DNA ( $>0.1 \mathrm{pg})$, it is a more rapid technique and can easily differentiate between host species in mixed bloodmeals sources in a single insect $[14,15]$. Furthermore, combining bloodmeal analysis with parasite 
detection in one Multiplex PCR-based RLB hybridization assay can be used for identifying the vectorial role of sandfly species and the reservoir status of various mammalian hosts [27]. Therefore, all these better qualities of PCR-RLB in comparison with ELISA are useful in studying bloodmeal sources in vectors of zoonotic diseases in general and leishmaniasis in particular for vector incrimination and reservoir host determination.

Prominently, 17.0 \% in PCR-RLB and 7.7 \% in ELISA assays of the bloodmeal samples were not from any of the eleven oligonucleotide probes or antibodies tested. These unidentified bloodmeals could belong to different species of wild animals found in the area. Alternatively, either degradation of residual host DNA [28] or the very small quantities of bloodmeals in case of ELISA [29] could be the possible reasons for the reduced detection success.

\section{Conclusions}

Our results demonstrated that the feeding preference of P. orientalis is primarily zoophilic, which possibly vary depending on the accessibility of bloodmeal hosts. Furthermore, the higher predilection of $P$. orientalis to bite cattle in the peridomiciliary could be exploited for killing sandfly vectors using insecticide treated animals. As sandflies ingest the blood from treated animals, they will ingest the blood with insecticide and adult sandflies die before oviposition, leading to suppression of sandfly population. Reductions in density of sandfly vectors around human dwellings represent a decrease in human-vector contact, which could play a crucial role in minimizing the exposure of people to $L$. donovani.

\section{Competing interests}

The authors declare that they have no competing interests.

\section{Authors' contributions}

$A G, A H, T G$ and $A W$ conceived the investigation. AG, SY, EA, AM and OK performed the fieldwork. AG, OK and IA conducted the molecular analysis. $A G, H T, M B, A H, T G$, and $A W$ analyzed the data and prepared the manuscript. All authors contributed to the final draft, and have read and approved the final manuscript.

\section{Acknowledgements}

We gratefully thank our field assistants Haile Gebremariam and Mehari Naizgi, for their help with collection and processing of sandfly specimens. We are also indebted to the people of Tahtay Adiyabo villagers for their kind co-operation. This study was supported by the Bill and Melinda Gates Foundation Global Health Program (grant number OPPGH5336).

\footnotetext{
Author details

'Department of Zoological Sciences, Addis Ababa University, Addis Ababa, Ethiopia. ${ }^{2}$ Department of Biology, College of Natural Science, Jigjiga University, Jigjiga, Ethiopia. ${ }^{3}$ Department of Microbiology and Molecular Genetics, The Institute of Medical Research Israel-Canada The Kuvin Center for the Study of Infectious and Tropical Diseases, Faculty of Medicine, The Hebrew University, Hadassah Medical School, Jerusalem, Israel. ${ }^{4}$ Aklilu Lemma Institute of Pathobiology, Addis Ababa University, Addis Ababa, Ethiopia. ${ }^{5}$ Department of Microbiology, Immunology and Parasitology, College of Health Sciences, Addis Ababa University, Addis Ababa, Ethiopia.
}

Received: 11 March 2015 Accepted: 4 May 2015

Published online: 13 May 2015

\section{References}

1. Desjeux P. Leishmaniasis: current situation and new perspectives. Comp Imunnol Microbiol Infect Dis. 2004;27:305-18.

2. Alvar J, Vélez ID, Bern C, Herrero M, Desjeux P, Cano J, et al. Leishmaniasis worldwide and global estimates of its incidence. PLoS One. 2012;7, e35671.

3. Ali A, Ashford RW. Visceral leishmaniasis in Ethiopia. IV. Prevalence, incidence and relation of infection to disease in an endemic area. Ann Trop Med Parasitol. 1994;88:289-93.

4. Lyons S, Veeken H, Long J. Visceral leishmaniasis and HIV in Tigray, Ethiopia. Trop Med Int Health. 2003;8:733-9.

5. Hailu A, Gebre-Michael T, Berhe N, Balkew M. Leishmaniasis in Ethiopia. In: Berhane $Y$, Haile-Mariam D, Kloos H, editors. The Ecology and Epidemiology of Health and Disease in Ethiopia. 1st ed. Addis Ababa: Shama Books; 2006. p. 615-34.

6. Abbasi I, Aramin S, Hailu A, Shiferaw W, Kassahun A, Belay S, et al. Evaluation of PCR procedures for detecting and quantifying Leishmania donovani DNA in large numbers of dried human blood samples from a visceral leishmaniasis focus in Northern Ethiopia. BMC Infect Dis. 2013;13:153.

7. Killick-Kendrick R. The biology and control of phlebotomine sandflies. Clin Dermatol. 1999;17:279-89.

8. Ready PD. Biology of phlebotomine sandflies as vectors of disease agents. Annu Rev Entomol. 2013:58:227-50.

9. Elnaiem DA, Ward RD, Hassan HK, Miles MA, Frame LA. Infection rates of Leishmania donovani in Phlebotomus orientalis from a focus of visceral leishmaniasis in eastern Sudan. Ann Trop Med Parasitol. 1998;92:229-32.

10. Hailu A, Balkew M, Berhe N, Meredith S, Gemetchu T. Is Phelotomus (Larroussius) orientalis a vector of visceral leishmaniasis in south-west Ethiopia? Acta Trop. 1995;60:15-20.

11. Gebre-Michael T, Balkew M, Berhe N, Hailu A, Mekonnen Y. Further studies on the phlebotomine sandflies of the kala-azar endemic lowlands of Humera-Metema (north-west Ethiopia) with observations on their natural blood meal sources. Parasit Vectors. 2010;3:6.

12. Ngumbi PM, Lawyer PG, Johnson RN, Killu G, Asiago C. Identification of sandfly blood meals from Baringo district, Kenya, by direct enzyme linked immunosorbent assays (ELISA). Med Vet Entomol. 1992;6:385-8.

13. Bongiorno G, Habluetzel A, Khoury C, Maroli M. Host preference of phlebotomine sandflies at a hypoendemic focus of canine leishmaniasis in central Italy. Acta Trop. 2003:88:109-16.

14. Abbasi I, Cunio R, Warburg A. Identification of blood meals imbibed by phlebotomine sandflies using cytochrome $b$ PCR and reverse line blotting. Vect Borne Zoon Dis. 2009;9:79-86.

15. Garlapati RB, Abbasi I, Warburg A, Poché D, Poché R. Identification of bloodmeals in wild caught blood fed Phlebotomus argentipes (Diptera: Psychodidae) using cytochrome $b$ PCR and reverse line blotting in Bihar, India. J Med Entomol. 2012;49:515-21.

16. Mamo H. Production of specific antisera against selected mammals and identification of bloodmeals of phlebotomine sand flies transmitting visceral leishmaniasis in Ethiopia, MSc thesis. Addis Ababa: Addis Ababa University, Biology Department; 1999.

17. Quate LW. Leishmaniasis in Sudan Republic. 19. Phlebotomus sandflies of the Paloich area in the Sudan (Diptera, Psychodidae). J Med Entomol. 1964;1:19-23.

18. Abonnenc E, Minter DM. Bilingual keys for the identification of the sandflies of the Ethiopian Region (in Fr. and Eng.). Mém Off Rech Sci Tech Outre-Mer Entomol Med. 1965:5:1-63.

19. Beier JC, Perkins PV, Wirtz RA, Koros J, Diggs D, Gargan TP, et al. Bloodmeal identification by direct Enzyme-Linked Immunosorbent Assay (ELISA), tested on Anopheles (Diptera: Culicidae) in Kenya. J Med Entomol. 1988;25:9-16.

20. Lemma W, Tekie H, Abassi I, Balkew M, Gebre-Michael T, Warburg A, et al. Nocturnal activities and host preferences of Phlebotomus orientalis in extradomestic habitats of Kafta-Humera lowlands, Kala-azar endemic. Northwest Ethiopia Parasit Vectors. 2014;7:594

21. Mukhopadhayay AA, Chakravarty AK. Bloodmeal preference of Phlebotomus argentipes and $P$. papatasi of north Bihar, India. Indian J Med Res. 1987;86:475-80.

22. Ghosh KN, Bhattacharya A, Ghosh TN. Bloodmeal analysis of Phlebotomus argentipes in eight districts of West Bengal. J Com Dis. 1990;22:67-71. 
23. Quinnell RJ, Dye C, Shaw JJ. Host preferences of the phlebotomine sandfly Lutzomyia longipalpis (Diptera: Psychodidae) in Amazonian Brazil. Med Vet Entomol. 1992;6:195-200

24. Hamilton JGC, Ramsoondar TMC. Attraction of Lutzomyia longipalpis to human skin odors. Med Vet Entomol. 1994;8:375-80.

25. Gebresilassie A, Yared S, Aklilu E, Kirstein OD, Moncaz A, Tekie H, et al. Host choice of Phlebotomus orientalis (Diptera: Psychodidae) in animal baited experiments: a field study in Tahtay Adiyabo district, northern Ethiopia. Parasit Vect. 2015;8:190.

26. Campbell-Lendrum DH, Pinto MC, Brandä̈-Filho SP, de Souza AA, Ready PD, Davies CR. Experimental comparison of anthropophily between geographically dispersed populations of Lutzomyia whitmani. J Med Entomol. 1999:13:299-309.

27. Kong F, Gilbert GL. Multiplex PCR-based reverse line blot hybridization assay (mPCR/RLB) — a practical epidemiological and diagnostic tool. Nat Protoc. 2006;1:2668-80.

28. Valinsky L, Ettinger C, Bar-Gal GK, Orshan L. Molecular identification of bloodmeals from sandflies and mosquitoes collected in Israel. J Med Entomol. 2014:51:678-85.

29. Maleki-Ravasan N, Oshaghi MA, Javadian E, Rassi Y, Sadraei J, Mohtarami F. Bloodmeal identification in field-captured sandflies: comparison of PCR-RFLP and ELISA assays. Iranian J Arthropod-Borne Dis. 2009;3:8-18.

\section{Submit your next manuscript to BioMed Central and take full advantage of:}

- Convenient online submission

- Thorough peer review

- No space constraints or color figure charges

- Immediate publication on acceptance

- Inclusion in PubMed, CAS, Scopus and Google Scholar

- Research which is freely available for redistribution 